\title{
Scorpion composition and scorpionism in a high-risk area, the southwest of Iran
}

Jalil Nejati ${ }^{1}$, Abedin Saghafipour ${ }^{2}$, Javad Rafinejad ${ }^{3}$, Ehsan Mozaffari $^{3}$, Amir Keyhani ${ }^{4}$, Ali Abolhasani ${ }^{5}$, Amir Tavakoli Kareshk ${ }^{6}$

${ }^{1}$ Health Promotion Research Center, Zahedan University of Medical Sciences, Zahedan, Iran

${ }^{2}$ Ph.D. in Medical Entomology, Department of Public Health, School of Health, Qom University of Medical Sciences, Qom, Iran

${ }^{3}$ Professor, Department of Medical Entomology \& Vector Control, School of Public Health, Tehran University of Medical Sciences. Tehran, Iran

${ }^{4}$ Department of Medical Parasitology, Kerman University of Medical Sciences, Kerman, Iran

${ }^{5}$ Department of Disease Control, Health Center of Andimeshk, Ahvaz Jundishapur University of Medical Sciences, Ahvaz, Iran

${ }^{6}$ Ph.D. in Medical Parasitology, Infectious Disease Research Center, Birjand University of Medical Sciences, Birjand, Iran

\section{Type of article: Original}

\begin{abstract}
Background: Scorpions are usually defined as predatory arachnids having venomous and painful stings. Scorpionism is considered as one of the health and medical problems in undeveloped tropical and subtropical countries in the world that endangers thousands of people annually.

Objective: This study was done for identification of scorpion fauna and scorpionism location in a high-risk area in southwest of Iran.

Methods: This study was carried out in Andimeshk district located in Khuzestan province which has the highest frequency of scorpionism in Iran. In total, 4 urban and 15 rural areas with various climates and topography were selected for monthly scorpion collection in 2016. Additionally, clinical data was obtained from questionnaires over a 5-year period (2012 to 2016) which were completed by physicians and health staff in hospitals and health centers. The data were analyzed by IBM-SPSS Version 20.

Results: A total of 850 scorpion samples with the most frequency in rural areas were collected. Eight species belonging to three families; Buthidae, Scorpionidae and Hemiscorpiidae were identified. A. crassicauda was the dominant species followed by $H$. lepturus. The largest collection due to scorpion's activity was recorded in summer. The five-year prevalence of scorpion sting were 9.1/1000 inhabitants. The highest frequency of scorpionism was observed in the male age group of 25-34 years. Most cases had been treated with polyvalent scorpion antivenom within 6-12 hours of the sting.

Conclusion: Based on the findings, six species of medically important scorpions that were previously reported from Iran were also collected and caught in this study area. The findings of this study can be useful for policymakers at the Andimeshk Healthcare Center to prevent scorpionism and provide appropriate treatment for scorpionism cases.
\end{abstract}

Keywords: Scorpion, Scorpionism, Andimeshk, Iran

\section{Introduction}

Scorpions are usually defined as predatory arachnids of the phylum arthropoda, class Arachnida and order Scorpionida. Their body length can be between 3 and $18 \mathrm{~cm}$ morphologically. The body of a scorpion is very tough

\section{Corresponding author:}

Amir Keyhani, Department of Medical Parasitology, Kerman University of Medical Sciences, Kerman, Iran.

Tel: +98.9168902297, E-mail: amir.keyhani59@yahoo.com

Received: February 15, 2017, Accepted: January 18, 2018, Published: July 2018

iThenticate screening: October 26, 2017, English editing: April 26, 2018, Quality control: May 15, 2018

This article has been reviewed / commented by four experts

(C) 2018 The Authors. This is an open access article under the terms of the Creative Commons Attribution-NonCommercialNoDerivs License, which permits use and distribution in any medium, provided the original work is properly cited, the use is non-commercial and no modifications or adaptations are made. 
and its toxic device is set on the end of its tail and contains two toxic glands, which are located in the thick chitin (1). Scorpions, as nocturnal creatures, are found in deserts, mountains, caves and also under rocks. When disturbed, they have been known to accidentally sting and endanger human lives (2). Only 25 scorpion species are lethal to humans, despite this, scorpions have caused fear among mankind since ancient times; often people think this creature is a killer to humans and their domestic animals. Scorpion venom is a protein material and is more used for catching insects and self-defense (1). Most species of this order of arachnids are only skilled predators for insects and small animals (3). The first documented report on a checklist of Iranian scorpions was the black scorpion Androctonus crassicauda, in Kashan, which was presented in 1807 by Olivier (4). Then, other researchers including Birula in 1903 reported two families (Scorpionidae \& Buthidae), 12 genera and 24 species of scorpions. Kovarik classified them into three families, 18 genera, 23 species and 17 subspecies $(5,6)$. Nowadays, scorpionism is one of the health and medical problems in undeveloped tropical and subtropical countries in the world, and endangers thousands of people annually. At present, scorpionism is a major health problem in South Africa, the Middle East, South America, Mexico and the Indian subcontinent. It was evaluated that about 1.2 billion people worldwide, live in areas where there is probability of scorpionism and about one million people are injured due to scorpion stings per year. This health problem has ultimately caused about $0.27 \%$ of mortality in the world annually (7). The deadliest scorpions, which live in North Africa and the Middle East, belong to the genus Buthus, Leiurus, Androctonus and Hottentotta. In South Africa, the deadliest scorpion is Tityus, in India it is Mesobuthus and in Mexico, Centruroides (8). Reported cases of scorpionism are variable in different geographical areas and different countries according to lifestyle, socio-economic status, housing, health-care quality and scorpion species to each area (9). Iran is located at 25-40 degrees' northern latitude which makes the country the most temperate zone on earth. Thereby, species' diversity and distribution of scorpions in Iran with regard to geographical location and climatic condition in each region is relatively impressive, but information about the exact biological characteristics and geographical distribution in the country can be inaccurate and limited (10). Deaths due to injury from scorpion stings are recorded in all regions of the country and approximately $75 \%$ of patients who have died from scorpion stings are reported from the three provinces of Khuzestan (which include Ahvaz, Andimeshk, and other cities), Sistan \& Baluchestan and Kerman (11). According to the literature reviews, although there were some scientific and valuable studies about scorpions in some areas of Khuzestan province (12-14), research on the scorpions' fauna and the epidemiology of their stings in Andimeshk district have been poorly investigated, as we only found one study of this area; the samples of this study were collected in 2001 (15). Bearing in mind the need for more information on scorpion species and lack of published papers about the epidemiological aspects of scorpionism in this area, this study was done for identification of scorpion fauna and scorpionism location. The findings of this investigation can be useful for risk management of scorpionism and prevention of this health problem in the future.

\section{Material and Methods}

This descriptive-analytic study was conducted in Andimeshk district located in Khuzestan province. Andimeshk district, is located in the north of Khuzestan province in the Southwest of Iran and has landmass of approximately $53,120 \mathrm{~km}^{2}$ (9.4\% of Khuzestan Province) with hot regions that are suitable for scorpion growth and reproduction. Its population is 167,126 . This area includes hilly areas, plains and foothills in rural and urban areas. The area has a temperate climate and relatively warm humid summer, and is located between $32^{\circ} 27^{\prime} \mathrm{N}$ latitude and $48^{\circ} 21^{\prime} \mathrm{E}$ longitude. The elevation of the study area ranges to 176 meters above sea level. The mean annual temperature in the area is between $12{ }^{\circ} \mathrm{C}$ and $42{ }^{\circ} \mathrm{C}$, and the mean precipitation is $402.5 \mathrm{~mm}$ annually. Also, its soil type is clay, and vegetation includes tamarisk shrubs and thorns.

\subsection{Scorpion collection and identification}

Scorpion collection was done during four seasons in 2016. Totally, 4 urban and 15 rural areas with variable climate and topography were selected for monthly scorpion collection through random cluster sampling. In each of the counties, 2-3 points were selected as sampling locations. The choice of locations was also considered plain or mountainous. Twenty-four locations were determined for scorpion collecting. Beginning at sunset and continuing for two hours, scorpions were searched for in plains and mountains with dense cover of weed such as camel thorn. Scorpions' nests could be located due to the semi-circular opening and existence of soil near to it. To entice the scorpions out of their nests, the nests were filled with water. The fleeing scorpions were then collected by the tail with long-handled tongs. Also, rocks were displaced with a metal lever in order to collect scorpions that may be sheltered under them. Another method was to use UV light to search for them. Spraying people's yards with water two hours before sunset, and then exploring the corners of the yard was another method. In warehouses, Pyrethroid spray was used to encourage the scorpions to leave their shelters. We also explored, under carpets, behind curtains, and around cupboards. The collected species were transferred to glass jars containing $70 \%$ ethanol, and labeled with 
the collector's name, the location and the date of sampling. In a laboratory at the Department of Medical Entomology and Vector Control at the School of Public Health, Tehran University of Medical Sciences, scorpions were identified using a stereo microscope and Farzanpay's key of identification (16).

\subsection{Clinical data collection}

The clinical data was obtained using questionnaires from the 5 years between 2012 and 2016. They were formerly prepared by the Iranian Center for Disease Control (CDC), and had been completed by physicians and health staff at hospitals and health centers, and collected at the Health Center of Khuzestan Province. The various data including patients' sex, age, residence, site of sting and antivenom injection status were derived from the questionnaires. IBMSPSS Version 20 was used for analyzing the gathered data. Also, the frequency of scorpions and human scorpion sting cases was determined. The five-year prevalence of scorpion stings was calculated based on the number of scorpion sting cases to mean population ratio from 2012-2016. In order to observe ethical considerations, demographic identification of patients remained hidden using code numbers (approval number: 930324, Kerman University of Medical Science).

\section{Results}

\subsection{Scorpion fauna}

In total, 850 samples were collected from urban and rural areas (Figure 1). Eight species belonged to 3 families; Buthidae, Scorpionidae and Hemiscorpiidae were identified and are shown in Table 1. Two species including Hottentotta zagrosensis (4.6\%) and Buthacus macrocentrus $(3.9 \%)$ were reported for the first time from this area. Androctonus crassicauda (27.3\%) was the dominant species followed by H. lepturus (22.1\%). Most of the captured scorpions were collected from rural areas 793 (93.3\%) with the frequency of females and males at $421(53.1 \%)$ and $372(46.9 \%)$ respectively. A further, 57 scorpions out of all captured specimens were collected in an urban area (Andimeshk district) with the frequency of females and males at $36(63.2 \%)$ and 21 (36.8\%) respectively. In total, the lowest population size was seen in Buthacus macrocentrus in rural and urban areas (Table 2). Most of the collected samples were found indoors, in yards, around the houses, and warehouses respectively. The most collected due to scorpion activity was recorded in summer 420 (49.4\%), followed by spring $311(36.6 \%)$ then Autumn 60 $(7.1 \%)$ and finally winter $59(6.9 \%)$.
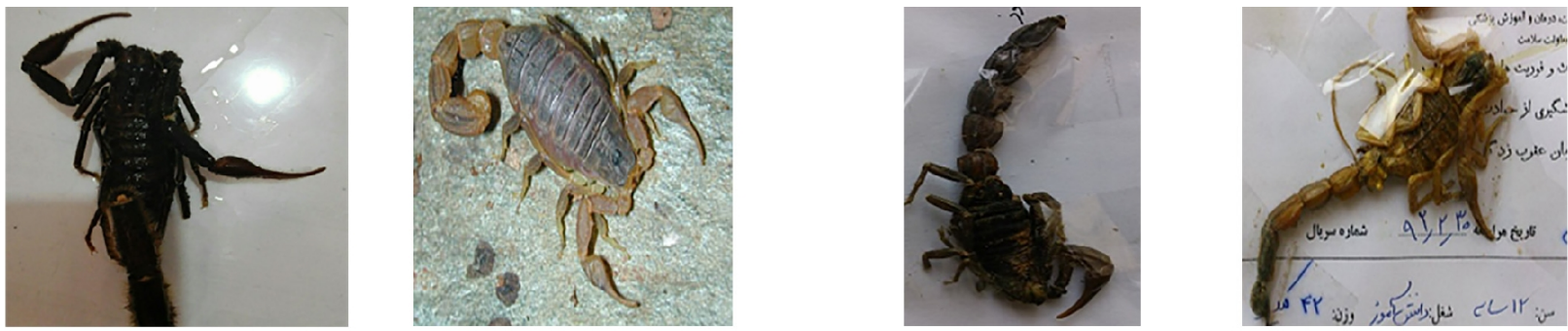

Hottentotta zagronesis Buthacus macrocentrus Androctonus crassicauda Mesobuthuse eupeus

Figure 1. Scorpion collected by victims, pasted on epidemiological questionnaire form, Andimeshk district, southwest Iran.

Table 1. Distribution and scorpion species composition in counties of Andimeshk district, southwest Iran, 2016

\begin{tabular}{|c|c|c|c|c|c|c|c|c|c|}
\hline \multirow[t]{2}{*}{ Sites } & \multicolumn{9}{|c|}{ Species; n (\%) } \\
\hline & $\begin{array}{l}\text { Mesobuthus } \\
\text { eupeus }\end{array}$ & $\begin{array}{l}\text { Androctonus } \\
\text { crassicauda }\end{array}$ & $\begin{array}{l}\text { Hemiscorpius } \\
\text { lepturus }\end{array}$ & $\begin{array}{l}\text { Odontobuthus } \\
\text { doriae }\end{array}$ & $\begin{array}{l}\text { Scorpio } \\
\text { maurus }\end{array}$ & $\begin{array}{l}\text { Hottentotta } \\
\text { saulcyi }\end{array}$ & $\begin{array}{l}\text { Hottentotta } \\
\text { schach }\end{array}$ & $\begin{array}{l}\text { Buthacus macro } \\
\text { centrus }\end{array}$ & Total \\
\hline Mazou & 32 & 65 & 39 & 15 & 23 & 12 & 9 & 13 & $208(24.5)$ \\
\hline Sorkhakan & 23 & 51 & 23 & 12 & 10 & 24 & 6 & 17 & $166(19.5)$ \\
\hline Bidroobe & 21 & 44 & 25 & 7 & 5 & 8 & 11 & 2 & $123(14.5)$ \\
\hline Hoseyniye & 11 & 27 & 31 & 10 & 6 & 19 & 8 & 1 & $113(13.3)$ \\
\hline Chamgolak & 10 & 17 & 41 & 0 & 13 & 17 & 3 & 0 & $101(11.9)$ \\
\hline Andimeshk & 4 & 19 & 0 & 4 & 10 & 18 & 2 & 0 & 57 (6.7) \\
\hline Azadi & 14 & 9 & 29 & 15 & 12 & 3 & 0 & 0 & $2(9.6)$ \\
\hline Total & $115(13.5)$ & $232(27.3)$ & $188(22.1)$ & $63(7.4)$ & $79(9.3)$ & $101(11.9)$ & $39(4.6)$ & $33(3.9)$ & $850(100)$ \\
\hline
\end{tabular}

\subsection{Scorpionism}

The five-year prevalence of scorpion sting involved 9.1/1000 inhabitants (1.522/167.126). Most of whom were male $(58.3 \%)$. The highest frequency of scorpionism belonged to the age group of $25-34$ years old $(17.1 \%)$, and 
older than 65 years had the lowest (3.3\%). The most reported cases were scorpion stings in the legs (45.1\%) and then hands (33.1\%) (Table 3). Although there were a very small number of patients without antivenom injection, most of them had been treated with polyvalent scorpion antivenom (87. 9\%). A large number (44.4\%) were treated within 6-12 hours after being stung. No deaths were reported due to scorpion sting during the study.

Table 2. The scorpions captured according to species, sex and geographical area, Andimeshk district, southwest Iran, 2016

\begin{tabular}{|l|l|l|l|l|l|}
\hline Species & Captured scorpions; $\mathbf{n}(\%)$ & \multicolumn{2}{l}{ Sex; $\mathbf{n}(\%)$} & \multicolumn{2}{l|}{ Geographical area; $\mathbf{n}(\%)$} \\
\cline { 3 - 6 } & & Male & Female & Rural & Urban \\
\hline Androctonus crassicauda & $232(27.3)$ & $72(31.1)$ & $160(68.9)$ & $213(91.8)$ & $19(8.2)$ \\
\hline Hemiscorpius lepturus & $188(22.1)$ & $79(42.0)$ & $109(58.0)$ & $188(100)$ & $0(0.0)$ \\
\hline Mesobuthuse eupeus & $115(13.5)$ & $39(33.9)$ & $76(66.1)$ & $111(96.5)$ & $4(3.5)$ \\
\hline Hottentotta saulcyi & $101(11.9)$ & $52(51.5)$ & $49(48.5)$ & $83(82.2)$ & $18(17.8)$ \\
\hline Scorpio maurus & $79(9.3)$ & $39(49.4)$ & $40(50.6)$ & $69(87.3)$ & $10(12.7)$ \\
\hline Odontobuthus doriae & $63(7.4)$ & $19(30.2)$ & $44(69.8)$ & $59(93.7)$ & $4(6.3)$ \\
\hline Hottentotta zagronesis & $39(4.6)$ & $22(56.4)$ & $17(43.6)$ & $37(94.9)$ & $2(5.1)$ \\
\hline Buthacus macrocentrus & $33(3.9)$ & $13(39.4)$ & $20(60.6)$ & $33(100)$ & $0(0.0)$ \\
\hline Total & $850(100)$ & $335(39.4)$ & $515(60.6)$ & $793(93.3)$ & $57(6.7)$ \\
\hline
\end{tabular}

Table 3. Scorpion sting site among the studied cases, Andimeshk district, southwest Iran

\begin{tabular}{|l|l|l|l|l|l|l|l|}
\hline \multirow{2}{*}{ Sting site } & \multicolumn{9}{|c|}{ Number of patients in $2012-2016$} & \multicolumn{2}{l|}{ Total } \\
\cline { 2 - 9 } & 2012 & 2013 & 2014 & 2015 & 2016 & n & $\%$ \\
\hline Head \& trunk & 90 & 66 & 90 & 48 & 38 & 332 & 21.8 \\
\hline Hand & 154 & 134 & 68 & 86 & 62 & 504 & 33.1 \\
\hline Leg & 166 & 134 & 152 & 112 & 122 & 686 & 45.1 \\
\hline Total & 410 & 167 & 310 & 246 & 222 & 1522 & 100 \\
\hline
\end{tabular}

\section{Discussion}

In this study, 8 scorpion species were captured from rural and urban areas of Andimeshk district in Khuzestan province southwest Iran. The results of this entomological study have shown that two species of scorpions including Hottentotta zagronesis and Buthacus macrocentrus are reported for the first time from this area. Some species of scorpions such as Hemiscorpius kashkayi have been collected in recent studies in Andimeshk district, but they were not found in this present study (17). One of the possible reasons for not reporting this scorpion species can be the morphological similarity of $H$. kashkayi in comparison to H. lepturus. Perhaps this resemblance has made it more difficult for researchers to detect Hemiscorpius kashkayi and was also difficult for previous researchers to recognize this species. Androctonus crassicauda, M. tamulus, M. eupeus, Parabuthus liosoma, Buthus occipitanus and Leiurus quinquestriatus are recognized as medically important scorpion species in the Middle East (18). To date, 64 species of scorpions belonging to three families (Buthidae, Scorpionidae and Hemiscorpiidae) have been reported in Iran (19) along with 12 species of medically important scorpions (20). With this situation, Iran has the most number of scorpions among Middle Eastern countries (21), and there may be more yet to be discovered (22). Of the 12 medically important scorpions in Iran (23), Orthochirus scrobiculosus, Apistobuthus pterygocercus, Mesobuthus caucasicus, Hemiscorpius acanthocercus, Compsobuthus matthiesseni were not found in this study. In the current study, H. lepturus was collected from indoors and outdoors. This scorpion was captured from under rocks, crevices and barrows of mud walls, under tree barks and anywhere that had moist soil. Hemiscorpius lepturus is the most dangerous scorpion in some areas of Iran such as Khuzestan, the hot and humid province in the south west (12). The species is responsible for deaths of many people in hot and humid provinces annually, not only in Khuzestan but also in Hormozgan. Severe and fatal hemolysis, acute renal failure, necrotic and deep ulcers, ankylosis of the joints, temporary and permanent psychosis and deaths are complications observed flowing $H$. lepturus stings (24). The heat and humidity can be considered as limited factors for breeding places of this species. In many areas of the country, the annual average temperature is high and the required humidity is not suitable for this scorpion. For this reason, this scorpion species has limited geographical extent (13). The present study demonstrated that M. eupeus, as an important scorpion species, was collected with the most abundance in various climates in rural as well as urban areas in Andimeshk district. Previously, researchers had captured H. lepturus in a number of areas in Iran, in a variety of climates and weather conditions from snowy highlands to tropical regions. Existence of this species in different countries such as Afghanistan, Armenia, Central Asia, China, Iraq, Turkey and Oman can confirm its adaptation to various climatic conditions $(25,26)$. According to the results of the present study, $O$. doriae was observed in the 
Andimeshk district. It has been proven previously that this species of scorpion has a widespread geographical distribution in Iran $(27,28)$. Along with H. lepturus, it is placed in the most dangerous scorpion group (9). In this present study, $O$. doriae was collected in all rural and urban areas. Similarly, it was captured from rural areas in Ilam province, west of Iran (29). Androctonus crassicauda, as another medically important species has been reported from Iran, Egypt, Jordan, Syria, Turkey, Iraq, Saudi Arabia and Azerbaijan (30) and was also collected in our field study. Androctonus crassicauda is called the black scorpion, known as a non-digging species with a size up to $12 \mathrm{~cm}$ in length. The results of previous studies indicated $28 \%$ of scorpionism cases belonged to this scorpion in the west of Iran $(31,32)$. Severe pain in patients and more deaths in infants due to its sting have been observed (33). Hottentotta saulcyi was also collected in this study. Type locality and repository of this species was Mosul, Iraq. But it can be found in the Iranian provinces of Chaharmahal \& Bakhtiyari, Hamadan, Hormozgan, Ilam, Kermanshah, Khouzestan, Kohgiluyeh \& Boyer-Ahmad, and Lorestan (34) as well as in neighboring Afghanistan, Iraq, and Turkey $(6,35,36)$. The other species captured in this area was Buthacus macrocentrus. Its distribution in Iran includes Bushehr province, Chahak district; Hormozgan and Khouzestan provinces $(14,37)$. This species has also been recorded in Iraq, Israel, Jordan, Syria, and Turkey $(35,38,39)$. Although the study area has a desert climate, various small climates and different geographical locations were chosen; Andimeshk district, Chamgolak and Azadi have semi-desert climate with plain topography, Bidroobe, Mazou and Sorkhakan are mountainous rural areas. The plain regions had the highest number and variety of collected species and the lowest belonged to the mountainous area. It seems that various climates and altitudes can affect the amount of scorpion species. Review of the literature confirms this assessment too. A study on association between scorpion composition and altitude in Argentina has shown that the low altitudes had the most diverse and greatest abundance, but no clear pattern has been identified in high altitudes (40). The genus Androctonus and Mesobuthus are found in various climates and different altitudes from $5 \mathrm{~m}$ to heights of $2000 \mathrm{~m}$ (41). Similarly, M. eupeus and A. crassicauda were collected from both plain and mountainous regions in the current study. Also, from a research in Algeria, it can be inferred that scorpionism is a climatology dependent accident (42). This study showed that most scorpions' activity was recorded in summer. This result has been reported in similar studies in Iran and is in agreement with the results of other countries such as Greece and Asian tropical countries (25, 31, 42-46). In Algeria, a research showed that the temperature and sunshine as climate variables affected scorpion activity (42). In addition to scorpion fauna investigation, in the second part of this present study, we studied the variables of scorpion sting cases in Andimeshk County, separately. According to the results of many studies which have been done, most scorpionism cases were male $(45,47)$. Our result is similar too, unlike other research which has shown a higher frequency in females. The high numbers of women who work as farmland laborers, as well as the lack of knowledge about scorpion stings have been expressed as the reasons for these results $(25,43)$. The results of our study have revealed that the age group of 15-24 years is considered as a high risk group, and literature reviews have indicated similar results $(9,25$, 43). Some researchers have determined that age can be a risk factor and they believe that the more scorpionism among young people is due to their work out of the home (43). But some studies have shown a slight difference to these results. An age group of 21-30 years old was presented as the worst affected age group in a research on scorpionism in the Riyadh region of Saudi Arabia (48). However, this may be due to a difference in the classification of age groups. Hands were sting sites with the most incidences recorded in similar studies $(9,25,43)$ as well as ours. In contrast, other studies have indicated the highest frequency of scorpion stings at the lower limbs. Wearing sandals or going barefooted during walking especially at night, have been expressed as the reason for this result (48). This difference may be concerned with socio-economic structure, as discussed in a Turkish study (49). In our study, most of the patients were treated with scorpion antivenom, although some of them were not treated at all. Similar results from many countries involved with scorpionism such as Iran, Saudi Arabia, Mexico, Argentina and Morocco $(25,48)$ have been reported, although treatment of all patients was also recorded in some of the papers (9). This difference in results is at issue (50). Some characteristics in patients such as having no systemic manifestations and low levels of catecholamines can give reason for prescription without antivenom. Nevertheless, some researchers have stressed the necessity for the compilation of a standard protocol for patients' treatment with antivenom and drugs (51). Early access to a health center following scorpion sting can be considered as a crucial factor in the prevention of death (52). Some researchers have also expressed that serotherapy should be administered immediately after scorpion sting for sufficient effectiveness. They have also stated that antivenom injection should be carried out regardless of the time elapsed between sting and treatment (53). Our study indicated that most patients received medical care within 6 hours from the time of sting. Comparable results can be seen in research conducted in various parts of Iran (25), although some results have recorded antivenom injection within three hours of the accident (9). Furthermore, an elapsed time of less than 30 minutes has been reported in an urban area in Saudi Arabia (48). Type of region (rural or urban), topography and geographical location, difficulty in access to medical services due to locality, expanding status of health system and cultural-economic structure can be seen as the 
effective factors of this issue. The authors suggest an impact assessment of the mentioned variables on elapsed time between scorpion sting and medical attention in the study area or in other regions.

\section{Conclusions}

Six medically important scorpion species that were previously reported from Iran were also collected and caught in this study area. The findings of this study can be useful for policymakers in the Andimeshk Healthcare Center to prevent scorpionism, and provide appropriate treatment for scorpionism cases. The resident's awareness promotion for the prevention of scorpionism is recommended. Further clinical studies are also suggested.

\section{Acknowledgments:}

Great appreciation goes to personnel from the Centre for Disease Control and Prevention at Andimeshk, Jundishapur University of Medical Sciences, Ahvaz, Iran. We would like to sincerely thank Dr. Moloud Mohammadi (Assistant Professor of Medical Entomology, Urmia University of Medical Sciences) for the species identification.

\section{Conflict of Interest:}

There is no conflict of interest to be declared.

\section{Authors' contributions:}

All authors contributed to this project and article equally. All authors read and approved the final manuscript.

\section{References:}

1) Keegan HL. Scorpions of medical importance. Mississippi: Mississippi University Press; 1980: 140.

2) Mirshamsi O, Sari A, Hosseinie S. History of study and checklist of the scorpion fauna (Arachnida: Scorpiones) of Iran. Prog Biol Sci. 2011; 1(2): 16-28.

3) Weygoldt P. Notes on the life history and reproductive biology of the giant whip scorpion, mastigoproctus giganteus (Uropygi, Thelyphonidae) from Florida. J Zoology. 1971; 164(2): 137-47. doi: 10.1111/j.14697998.1971.tb01301.x.

4) Farzanpay R. Knowing scorpions. Tehran: Central University Publications; 1987: 231.

5) Birula A. Beitrage zur kenntniss der scorpionenfauna ost-persiens. II. Bull Acad Imp Sci. 1903; 19(2): 6780.

6) Kovarik F. Results of the Czech biological expedition to Iran. Acta Soc Zoll Bohem. 1997; 61: 39-52.

7) William SC. Scorpion bionomics. Ann Rev Entomol. 1987; 32(1): 275-95. doi: 10.1146/annurev.en.32.010187.001423. PMID: 3545055.

8) Prendini L, Wheeler WC. Scorpion higher phylogeny and classification, taxonomic anarchy, and standards for peer review in online publishing. Cladistics. 2005; 21(5): 446-94. doi: 10.1111/j.10960031.2005.00073.x.

9) Kassiri H, Teimouri A, Shemshad M, Sharifinia N, Shemshad K. Epidemiological survey and clinical presentation on scorpionism in South- West of Iran. Middle East J Sci Res. 2012; 12(3): 325-30.

10) Fet V, Soleglad ME. Contributions to scorpion systematics. I. On recent changes in high-level taxonomy. Euscorpius. 2013; 2005(31): 1-13.

11) Dehghani R, Vazirianzadeh B, Nasrabadi MR, Moravvej SA. Study of scorpionism in Kashan in central Iran. Pakistan J Med Sci. 2010; 26(4): 955-8.

12) Akbari A, Tabatabei SM, Hedayat A, Modir Roosta H, Alizadeh MH, Kamalzare M. A study of the geographical distribution of the scorpions in the south of Iran. Pajouhesh va Sazandegi. 1997; 34: 112-5.

13) Dehghani R, Bigdelli S. Surveying the habitats on Hemiscorpius lepturus scorpion in Khuzestan province (Scorpionida-Scorpionidae) Pajouhesh \& Sazandegi. 2006; 20(2): 81-7.

14) Navidpour S, Kovařík F, Soleglad ME, Fet V. Scorpions of Iran (Arachnida, Scorpiones). Part I. Khuzestan Province. Euscorpius. 2008; 65: 1-41.

15) Sampour M. Distribution of Scorpions (Arachnida: Scorpiones) of Alvar, Northpart of Andimeshk in the North of Khuzestan Province, Southwest Iran. Journal of Applied Science and Agriculture. 2014; 9(6): 2406-11.

16) Farzanpay R. A catalogue of the scorpions occurring in Iran, up to January 1986. Archives de l'Institut Razi. 1990.

17) Karatas A, Gharkheloo MM. A new Hemiscorpius Peters, 1861 (Scorpiones: Hemiscorpiidae) from southwestern Iran. Turkish Journal of Zoology. 2013; 37: 15-23. 
18) Bawaskar HS, Bawaskar PH. Scorpion sting: update. J Assoc Physicians India. 2012; 60(1): 46-55. PMID: 22715546.

19) Motevalli Haghi F, Dehghani R. A Review of Scorpions Reported in Iran. J Mazandaran Univ Med Sci. 2017; 27(151): 213-26.

20) Sanaei-Zadeh H, Marashi SM, Dehghani R. Epidemiological and clinical characteristics of scorpionism in Shiraz (2012-2016); development of a clinical severity grading for Iranian scorpion envenomation. Med J Islam Repub Iran. 2017; 31(1):158-66. doi: 10.18869/mjiri.31.27. PMID: 29445656, PMCID: PMC5804458.

21) Dehghani R, Fathi B. Scorpion sting in Iran: a review. Toxicon. 2012; 60(5): 919-33. doi: 10.1016/j.toxicon.2012.06.002. PMID: 22750221.

22) Sedaghat M, Salehi Moghadam A, Dehghani R. Mapping the distribution of some important scorpions collected in the past five decades in Iran. HBI Journals. 2012; 9(4): 285-96.

23) Sanaei-Zadeh. Painless stings of yellow Iranian scorpions. Iran Red Crescent Med J. 2017; 19(4): e42645. PMID: 25183084, PMCID: PMC4025348.

24) Nejati J, Saghafipour A, Mozaffari E, Keyhani A, Jesri N. Scorpions and scorpionism in Iran's central desert. Acta Trop. 2017; 166: 293-8. doi: 10.1016/j.actatropica.2016.12.003. PMID: 27923555.

25) Nejati J, Mozafari E, Saghafipour A, Keyani M. Scorpion fauna and epidemiological aspects of scorpionism in southeastern Iran. Asian Pacific journal of tropical biomedicine. 2014; 4: S217-21.

26) Karataş A, Gharkheloo MM. A contribution to the knowledge of Hottentotta saulcyi (Simon, 1880) (Scorpiones: Buthidae). Zoology in the Middle East. 2006; 38(1): 85-92. doi: 10.1080/09397140.2006.10638169.

27) Pirali-Kheirabadi K, Navidpour S, Fet V, Kovař́k F, Soleglad ME. Scorpions of Iran (Arachnida, Scorpiones). Part V. Chahar Mahal and Bakhtiyari Province. Euscorpius. 2009; 78: 1-23.

28) Navidpour S, Fet V, Kovařík F, Soleglad ME. Scorpions of Iran (Arachnida, Scorpiones). Part VIII. Fars Province. Euscorpius. 2015; 2012(139): 1-29.

29) Mozaffari E, Sedaghat MM, Sanei-Dehkordi AR, Akbarzadeh K. Bidiversity and species composition of scorpions (Arachnida, Scorpiones) in Ilam County, Iran. J Applied Sci Res. 2013; 9: 5412-8.

30) Karataş A, Çolak M. Scorpions of Gaziantep Province, Turkey (Arachnida: Scorpiones). Euscorpius. 2015; 2005(30): 1-7.

31) Vazirianzadeh B, Salahshoor A. Scorpion Sting in Izeh, Iran: An Epidemiological Study During 20092011. Journal of Basic \& Applied Sciences. 2015; 11: 403. doi: 10.6000/1927-5129.2015.11.57.

32) Aghabiklooei A, Zamani N, Hassanian-Moghaddam H. Getting stung by black scorpion Androctonus crassicauda: A case report. Human \& Experimental Toxicology. 2013; 33(10): 1081 -4.

33) Khodadadi A, Pipelzadeh MH, Vazirianzadeh B, Pipelzadeh M, Sharifat M. An in vitro comparative study upon the toxic properties of the venoms from Hemiscorpius lepturus, Androctonus crassicauda and Mesobuthus eupeus scorpions. Toxicon. 2012; 60(3): 385-90. doi: 10.1016/j.toxicon.2012.04.348. PMID: 22569320 .

34) Kovařík F. A revision of the genus Hottentotta Birula, 1908, with descriptions of four new species (Scorpiones,Buthidae). Euscorpius. 2007; 58: 1-107.

35) Crucitti P, Vignoli V. Gli scorpioni (Scorpiones) dell'Anatolia sud-orientale (Turchia). Boll Mus Reg Sci Nat Torino. 2002; 19(2): 433-80.

36) Yağmur EA, Koç H, Yalçın M. Distribution of Hottentotta saulcyi (Simon, 1880) (Scorpiones: Buthidae) in Turkey. Euscorpius. 2008; 76: 1-6.

37) Kovařík F. Taxonomic position of species of the genus Buthacus Birula, 1908 described by Ehrenberg and Lourenço, and description of a new species (Scorpiones: Buthidae). Euscorpius. 2005; 28: 1-13.

38) Vachon M. Liste des scorpions connus en Egypte, Arabie, Israël, Liban, Syrie, Jordanie, Turquie, Irak, Iran. Toxicon. 1966; 4: 209-18. doi: 10.1016/0041-0101(66)90052-3.

39) Pérez SM. Un inventario preliminary de los escorpiones de la region Palearctica y claves para la identificacion de los generous de la region Palearctica Occidental. Dt Zool Fac Cienc Madrid Cat Artr. 1974; 7: 1-45.

40) Campón FF, Silnik SL, Fedeli L. Scorpion diversity of the Central Andes in Argentina. The Journal of Arachnology. 2014; 42(2): 163-9. doi: 10.1636/P13-30.1.

41) Jalali A, Rahim F. Epidemiological review of scorpion envenomation in Iran. Iranian journal of pharmaceutical research. 2014; 13(3): 743-56. PMID: 25276176, PMCID: PMC4177636.

42) Selmane S, El Hadj H, Benferhat L. The Impact of Climate Variables on the Incidence of Scorpion Stings in Humans in M'Sila's Province in Algeria. Proceedings of the World Congress on Engineering; 2014. 
43) Kassiri H, Shemshad K, Kassiri A, Shemshad M, Valipor AA, Teimori A. Epidemiological and climatological factors influencing on scorpion envenoming in Baghmalek County, Iran. Acad J Entomol. 2013; 6(2): 47-54. doi: 10.1016/S2222-1808(14)60632-0.

44) Kaltsas D, Stathi I, Mylonas M. The effect of insularity on the seasonal population structure of Mesobuthus gibbosus (Scorpiones: Buthidae). Euscorpius. 2015; 2006(44): 1-8.

45) Kassiri H, Kasiri A, Kasiri E, Abdian P, Matori F, Lotfi M. Epidemiological characteristics and incidence rate of definite scorpion stings in Mahshahr County, Iran: multivariate analysis of 1635 cases. Asian Pacific Journal of Tropical Disease. 2015; 5(1): 80-4.

46) Gomes A, Gomes A. Scorpion Venom Research Around the World: Heterometrus Species. Scorpion Venoms: Springer. 2015: 351-67. PMID: 25451014.

47) Konca C, Tekin M, Genc Y, Turgut M. Epidemiological and Clinical Characteristics and Outcomes of Scorpion Envenomation in Hospitalized Children in Adiyaman, Turkey. Iran J Pediatr. 2015; 25(1): e199. doi: 10.5812/ijp.199. PMID: 26199687, PMCID: PMC4505969.

48) Al Asmari AK, Al Zahrani AG, Al Jowhary S, Arshaduddin M. Clinical aspects and frequency of scorpion stings in the Riyadh Region of Saudi Arabia. Saudi medical journal. 2012; 33(8): 852-8. PMID: 22886117.

49) Ozkan O, Adiguzel S, Yakistiran S, Cesaretli Y, Orman M, Karaer KZ. Androctonus crassicauda (Olivier 1807) scorpionism in the Sanliurfa Provinces of Turkey. Acta Parasitol Turcica. 2006; 30: 239-45.

50) De Roodt AR. Comments on environmental and sanitary aspects of the scorpionism by Tityus trivittatus in Buenos Aires City, Argentina. Toxins. 2014; 6(4): 1434-52. doi: 10.3390/toxins6041434. PMID: 24759176, PMCID: PMC4014744.

51) Natu V, Kamerkar S, Geeta K, Vidya K, Natu V, Sane S, et al. Efficacy of anti-scorpion venom serum over prazosin in the management of severe scorpion envenomation. J Postgrad Med. 2010; 56(4): 275-80. doi: 10.4103/0022-3859.70938. PMID: 20935398.

52) Vahdati SS, Moradi M. Scorpion bite; a natural problem. Turkish J Emerg Med. 2012; 12(4): 149. doi: 10.5505/1304.7361.2012.96720.

53) Ghalim N, El-Hafny B, Sebti F, Heikel J, Lazar N, Moustanir R, et al. Scorpion envenomation and serotherapy in Morocco. The American journal of tropical medicine and hygiene. 2000; 62(2): 277-83. doi: 10.4269/ajtmh.2000.62.277. PMID: 10813485. 